\title{
Research and Practice of Internationalization of Postgraduate Education Under the perspective of "Chinese-foreign Cooperatively-run Schools Upgrade Version"
}

\author{
Yu-zhouSUN ${ }^{1}$, Lu-junCUI ${ }^{2}$, Xiao-huaMA ${ }^{1 *}$, Xiao-weiTU ${ }^{3}$ \\ ${ }^{1}$ Graduate Department of Zhongyuan University of Technology, Zhengzhou, Henan, 451191 \\ ${ }^{2}$ School of Mechanical and Electrical Engineering, Zhongyuan university of technology, Zhengzhou, Henan, 451191 \\ ${ }^{3}$ Internaional Ofiice of Zhongyuan University of Technology, Zhengzhou, Henan, 451191 \\ *Corresponding author. Email: maxiaohua277@126.com
}

\begin{abstract}
Graduate education is responsible for training high-level talents for the country and society. China is a big country in graduate education, but not a strong country in graduate education. In view of the problems hidden behind the "scale and quantity" development of graduate education, how to effectively improve the quality of graduate international training under the background of "upgraded version of Sino foreign cooperation in running schools", this paper discusses the innovation of graduate international communication mode and the expansion of international cooperation space. In order to promote the quality of international education of graduate students to a new level, we need to build a collaborative mechanism between domestic and foreign tutors, link up and integrate the international "double campus" training mode, and establish a quality assurance system to adapt to the international training.
\end{abstract}

Keywords: Chinese-foreign cooperatively-run schools, postgraduate education, internationalization

\section{INTRODUCTION}

The 《National Medium and Long-term Educational Reform and Development Plan (2010-2020)》 clearly stated: "Strengthen international exchanges and cooperation, carry out multi-level and wide-ranging educational exchanges and cooperation, improve the internationalization of China's education, and adapt to the national economy and society. The requirements of opening to the outside world have cultivated a large number of international talents with an international perspective, familiar with international rules, and able to participate in international affairs and international competition[1]." In January 2017, the Ministry of Education and the State Council jointly issued the 《 Degree and Graduate Education Development In the "Thirteenth Five-Year Plan 》, the main line for the development of postgraduate education that adheres to "service demand and quality improvement" is put forward for the first time, and the ideas, goals, tasks and measures for the development of postgraduate education in China during the "13th Five-Year Plan" are clearly put forward. International cooperation, enhancing international influence" is elaborated as a separate chapter, clearly proposing "establish the concept of open cooperation and win-win, adhere to the combination of bringing in and going out, actively participating in international exchanges and cooperation, and continuously expanding the international competitive advantage of graduate education" , This has pointed out the way and direction for the development of the internationalization of graduate education in our country[2]. The internationalization of graduate education is responsible for cultivating high-level talents for the country and society. The Ministry of Education of the People's Republic of China issued a document stating that the number of postgraduate students in my country will reach 3 million in 2020, and the enrollment will be expanded to 189,000 in 2020, including many international students from various countries. All figures convey such a message: my country has become a major postgraduate education country in the world. However, to become a strong country in graduate education and to be attractive to 
foreign students, the level of internationalization must be greatly improved. Through large-scale international training, shaping the new model of postgraduate education in my country's universities[2] is the focus of the international development of my country's higher education, and it is also a booster for China to move from a big country of higher education to a strong country of higher education[3] .

In the past few decades, the level of internationalization of postgraduate education in my country has been greatly improved. From the perspective of system construction alone, from the early credit system to the promotion of professional degrees in recent years and the recent engineering doctoral degree pilot program; from the emphasis on an independent master's degree to the direct continuous master-doctoral program, etc., all are the results of improving the international level. Other aspects such as expanding mutual recognition of academic qualifications between governments, exchanges of personnel including teachers and graduate students, joint training of Chinese and foreign degrees (such as Zhongyuan University of Technology and Brunel in the United Kingdom, etc.), until New York University and East China Normal University jointly run schools in Shanghai And so on, are the results of improving the internationalization of graduate education.

In recent years, Zhongyuan University of Technology has always adhered to open education, centered on the goal of "promoting the construction of high-level universities with internationalization", actively served the national "Belt and Road" initiative, and implemented the strategy of open and flexible schools. It has successively cooperated with Russia, Italy, Thailand, the United Kingdom, Germany, 55 educational institutions in 24 countries and regions, including the United States and Taiwan, carry out international cooperation and exchanges. ZhongyuanUniversity of Technology is also one of the first universities in Henan Province to carry out Sinoforeign cooperative education projects. Since 2002, our school has successively cooperated with universities such as the University of Manchester in the UK, Manchester Metropolitan University, and the National Institute of Technology in New Zealand to hold Sinoforeign cooperative education projects. In 2017, the non-independent legal person Sino-foreign cooperative education institution-"Zhongyuan University of Technology Zhongyuan Petersburg Aeronautical Institute", which was jointly sponsored by the school and the St. Petersburg State University of Aerospace Instrument Manufacturing of the Russian Federation, was approved by the Ministry of Education and began to recruit students. In July 2018, Wang Guosheng, secretary of the Henan Provincial Party Committee, visited the St. Petersburg State University of Aerospace Instrument Manufacturing. The two universities signed the "Aerospace Technology Collaborative Innovation Center" agreement, which was included in the major project of the "Belt and Road" construction in Henan Province. In May 2019, Xuanyuan College of Zhongyuan University of Technology, the first overseas branch established by our school in cooperation with Thailand Keller University, was officially approved for filing, and the first international students were recruited at the same time. The establishment of overseas branch schools marks a new breakthrough in our school's foreign cooperation in running schools, and international cooperation is moving towards a new path of two-way development of "bringing in" and "going out". The school conducts joint training of doctoral students with Brunel University in London and the University of Sao Paulo in Brazil. The school has launched the "Study Abroad Program" and set up special scholarships for foreign students. International students from Russia, South Korea, Tajikistan, Turkmenistan, Pakistan, Bangladesh, Egypt and other countries along the "Belt and Road" come to the school to learn Chinese, study for master's and graduate students, and international campus The atmosphere is strong.

Based on the school's early international education accumulation, Zhongyuan University of Technology recently put forward the goal of striving to build an upgraded version of Sino-foreign cooperative education, promote "second entrepreneurship", build a first-class high-level backbone university in China, and achieve "doctoral authorization, renamed university". The concept of "Sino-foreign Cooperation in Running Schools Upgraded Version" includes "emphasis on internationalization while strengthening connotation construction", "encourage going global while focusing on importing", "paying attention to quantity while pursuing quality", "paying attention to input and output at the same time". The concept of "Sino-foreign Cooperation in Running Schools Upgraded Edition" is more suitable for the cultivation of postgraduate international students, which will effectively promote the rapid development of the school's postgraduate international training, improve the quality of postgraduate training, and conceptually solve important issues that need to be resolved in the internationalization of graduate students.

The content of the internationalization of graduate education is very extensive. In recent years, there have been many discussions on this aspect [4-6], and these discussions have been extensively discussed in terms of curriculum reform and the introduction of foreign teaching materials. This article focuses on some discussions in terms of international exchanges, international construction of the teaching staff, and international training quality assurance. 


\section{INNOVATEINTERNATIONAL EXCHANGE METHODS FOR GRADUATE STUDENTS AND EXPAND THE SPACE FOR INTERNATIONAL COOPERATION}

At present, the types of Chinese-foreign cooperation in running schools show a trend of diversified development, which increases the diversity of education supply in China. The scale and level of running schools have been gradually raised. In addition, there are broad prospects for cooperation and greater openness, exchanges and integration between regions. International exchange and international innovation cooperation have brought the internationalization of higher education into a new stage of development.

Currently, domestic postgraduates' overseas (overseas) exchange channels mainly include participation in academic conferences, short-term study visits, exchanges, and $\mathrm{X}+\mathrm{Y}$ degree programs. The ways to recruit international students include exchange students, non-degree language students, and degree students. With the increasing frequency of China's foreign exchanges, various new forms of international communication have become possible. Zhongyuan Institute of Technology, under the background of the "upgraded version of Sino-foreign cooperation in running schools", innovated more effective international exchange methods for graduate students from the perspectives of focusing on training quality and output, graduate education, service and scientific research. For example, further optimize the school's existing Sinoforeign joint doctoral training model, integrate the school's discipline development, scientific research, and international project cooperation into Sino-foreign cooperation projects, and carry out substantive scientific research cooperation with foreign countries to enhance the school's scientific research competitiveness.

In addition, through the establishment of "virtual universities" and "virtual research institutes", the management of various foreign exchange projects and students is strengthened, and teachers and students are encouraged to strengthen exchanges and cooperation through these platforms, and implement various international cooperation projects. Innovative postgraduate international communication methods can lay a good foundation for the construction of international faculty and curriculum resources, give full play to the synergy of domestic and foreign tutors in postgraduate training, promote the reform of international postgraduate courses and teaching methods, and improve The quality of postgraduate internationalization is very important.

\section{COLLABORATIVE TRAINING OF INNOVATIVE AND INTERNATIONAL TEACHERS, ENRICHING THE INTERNATIONAL BACKGROUND OF INSTRUCTORS}

There are two forms of "going out" and "bringing in" for the training of international faculty. In recent years, many universities have introduced full-time foreign teachers. How to give full play to the role of these foreign teachers in the internationalization of graduate students is worthy of in-depth research. In addition, the joint training of postgraduates at home and abroad and the strengthening of exchanges and cooperation between domestic and foreign tutors will also play an important role in promoting international education. In the joint training of graduate students at home and abroad, an incentive and coordination mechanism for international training will be established, so that domestic and foreign tutors will cooperate throughout the entire training process of graduate students, and promote the internationalization of the domestic tutor team and training process. In the process of international postgraduate training, most postgraduates have to go through the "dual campus" training model. The creation of an international faculty team and international collaborative training can enable graduate students to achieve "dual campuses" in their life experiences and learning outcomes under the "dual campus" training model Seamless docking is an important part of improving the quality of postgraduate internationalization training. It is directly related to the management research of postgraduate international students, and effectively improves the quality of postgraduate internationalization training.

\section{INNOVATE THE INTERNATIONAL TRAINING QUALITY ASSURANCE SYSTEM AND IMPROVE THE POSTGRADUATE EVALUATION SYSTEM}

The international development of colleges and universities poses new challenges to the faculty. The weak construction of international teachers makes it difficult for universities to develop internationally. For a long time, local colleges and universities have a serious shortage of teachers with overseas background or international thinking and education concept, and the teaching force is relatively weak. For local universities, in order to rapidly promote the internationalization of talent cultivation, there is an urgent need for a highlevel international faculty team that is familiar with international standards. The development of education internationalization has put forward higher requirements for teachers. University teachers should not only have rich teaching experience, advanced teaching concepts and solid research ability, but also have a broad 
international vision, as well as cross-language and cross-cultural communication and application skills.

The postgraduate curriculum construction system under the vision of "Sino-foreign cooperation in running schools" is an important guarantee for the quality of training. First of all, it is feasible to explore the construction of curriculum resources shared by domestic and foreign students, pursuing the sharing of English courses by Chinese and foreign students, and English online courses and video courses by Chinese and foreign students. Secondly, in accordance with the requirements of the internationalization of graduate students, analyze the factors that affect the ability of graduate students and the current problems in the cultivation of graduate students from the external environment, internal environment and students' own conditions, and establish a quality evaluation system for the cultivation of graduate students. Focus on improving the ability evaluation indicators in the internationalization of graduate students, and constantly revise and improve the enrollment, curriculum, teaching methods, professional practice, faculty, and dissertations that are in line with the internationalization of university graduate students. On the one hand, the internationalized postgraduate evaluation system helps to quantitatively analyze the internationalization process of postgraduate education in universities, and facilitates self-evaluation and other evaluation by universities; on the other hand, through the formulation and assessment of the evaluation system, the goals of postgraduate education in the process of internationalization can be improved. Clearly, it will help improve the quality assurance system for international graduate students.

\section{CONCLUSION}

Therefore, Zhongyuan University of Technology under the background of the "upgraded version of Sinoforeign cooperation in running schools", based on "emphasis on internationalization while strengthening connotation construction", "encourage going global while focusing on bringing in", "pay attention to quantity while pursuing quality", and pay attention to investment at the same time. Pursuing output" and other concepts, by improving and perfecting the postgraduate international training mechanism, optimizing the postgraduate international training model, and enhancing the quality of postgraduate international training. Expand the space for international cooperation of graduate students, innovate the management model of international graduate students, build an international faculty team, innovate the international training quality assurance system, and effectively promote the quality of graduate international education to a new height.

\section{About the author:}

Sun Yuzhou (1974-), male, professor, School of Mechanical and Electrical Engineering, Zhongyuan university of technology. Mainly engaged in micro/nano mechanics and numerical simulation for engineering research.

\section{AUTHORS' CONTRIBUTIONS}

Yu-zhouSUNandLu-junCUI conceived and designed the study. Xiao-huaMA was in charge of the literature review.Xiao-weiTUwas in charge of conducting research visits.Yu-zhouSUN and Lu-junCUI wrote the paper.Xiao-huaMAand Xiao-weiTU reviewed and edited the manuscript. All authors read and approved the manuscript.

\section{ACKNOWLEDGMENTS}

This work is finically supported by the Henan Province Research and practice project of higher education teaching reform (Grant No.2019SJGLX025Y),Henan Province National Natural Science Foundation (Grant No.212300410422),Henan Province Project of Postgraduate education reform and quality improvement (NO.YJS2021AL042)

Project support: 2019 Henan Province Graduate Education Reform and Practice Project (Graduate Education) "Sino-foreign Cooperation in Running Schools Upgraded Edition" Perspective of Graduate Education Internationalization Research and Practice" (NO.2019SJGLX025Y); Henan Province Graduate Education Reform and Practice and 2021 Quality Improvement Project (Professional Degree Graduate Excellent Teaching Case Project) (NO.YJS2021AL042); School-level Graduate Education Quality Improvement Project "Research and Practice on Teaching Reform of 《Virtual Instrument Technology 》) Course Based on Blended Teaching"; School-level professional degree Postgraduate course teaching case library project " 《Virtual Instrument Technology》 teaching case library".

\section{REFERENCES}

[1] Chen Zhongqi. Promote the reform of graduate education and improve the internationalization of graduate education $[\mathrm{J}]$. Academic Degrees \& Graduate Education, 2011(12):1-4.

[2] LU Xiaobing, WANG Wenjun and QIAN Xiaolong. Retrospection and introspection on the theory and practice of higher education internationalization in China in the context of its"double first-class" initiative.[J]. Journal of Higher Education Management, 2018(1):27-34. 
[3] Zhou Dong, Ma Binbin and XieJigang.The Belt and Road Initiative-An Analysis of the Cultivation Model of Convergence Management for International Students in the Context-A Case Study of Postgraduates Studying in China in Guangxi Universities [J]. Learning Weekly, 2019,17: 178-179.

[4] Chai Guosheng, Zhang Tongxue, Wang Lili. Study on the internationalization and high quality development strategy of graduate education in local universities. [J]. Journal of Zhongyuan University of Technology, 2020,31(04):88-94.

[5] Yan Jiayu.Research on the Devolopment Motivations and path for Internationalization of graduate Education in China. [D].Xiangtan University, 2016.

[6] Huang Xin. Study on the International Cultivation of Graduate Students. [D].Tianjin University, 2011. 